\title{
SABERES DOCENTES E SUA RELEVÂNCIA NAS AULAS DE HISTÓRIA: UMA ANÁLISE DO USO DO CINEMA COMO RECURSO DIDÁTICO
}

\author{
TEACHING KNOWLEDGE AND ITS RELEVANCE IN HISTORY LESSONS: \\ AN ANALYSIS OF THE USE OF CINEMA AS A RESOURCE OF TEACHING
}

Vitória Duarte Wingert'1, Márcia Blanco Cardoso²

Recebido em: 06 de abril de 2017

Aprovado em: 28 de junho de 2017

Sistema de Avaliação: Double Blind Review

RPR | a. 14 | v. 2 | p. 131-146 | jul./dez. 2017

\section{RESUMO}

A presente pesquisa propõe-se a discutir o uso do cinema em sala de aula pelos professores de História, e como se dá essa formação e planejamento por parte dos docentes, a partir da teoria de Maurice Tardif. A partir disso foi realizado um estudo com os professores de História da rede municipal de ensino de Campo Bom/RS, reconhecida por espaços de formação continuada e estrutura adequada para utilização de tecnologias em sala de aula. A metodologia utilizada foi a pesquisa bibliográfica, a partir de autores como Ferro, Severo, Schimidt e Napolitano, entre outros, além de pesquisa qualitativa a partir de entrevistas estruturadas. Verificou-se que os professores utilizam esse recurso de variadas e criativas formas, como possibilidades de reflexão e análise de conceitos, épocas e alguns, inclusive, realizando produção fílmica.

Palavras-chave: Ensino de História. Cinema. Cinema em sala de aula. Saberes docentes. Campo Bom - RS.

\begin{abstract}
The present research proposes to discuss the use of cinema in the classroom by History teachers, and how this graduation and planning by teachers is given, based on the theory of Maurice Tardif. Based on this, a study was carried out with History teachers of Campo Bom/RS municipal school system, recognized for continuing education spaces and adequate structure for use of technologies in the classroom. The methodology used was the bibliographic research, based on authors such as Ferro, Severo, Schimidt and Napolitano, among others, besides qualitative research based on structured interviews. It was verified that the teachers use this resource of varied and creative forms, as possibilities of reflection and analysis of concepts, times and also producing films.

Keywords: History teaching. Movie theater. Cinema in the classroom. Teacher knowledge. Campo Bom - RS.
\end{abstract}

\section{INTRODUÇÃO}

O presente trabalho versa sobre alguns dos resultados obtidos na pesquisa final do Trabalho de Conclusão de Curso (TCC) em História - Licenciatura pela Universidade Feevale a qual, teve como objetivo "refletir sobre a importância do cinema como recurso didático nas aulas de História e as possibilidades de utilização desse recurso".

\footnotetext{
${ }^{1}$ Especializanda em Literatura Infanto-juvenil (Faculdade Internacional Signorelli/Brasil) e Ensino de Filosofia (Universidade Federal de Santa Maria/Brasil). E-mail: vitoriawingert@hotmail.com.

${ }^{2}$ Mestre em História (Universidade do Vale do Rio dos Sinos/Brasil). Professora na Universidade Feevale (Novo Hamburgo/Brasil). E-mail: mcardoso@ feevale.br.
} 
O grande diferencial dessa pesquisa, não é somente validar o uso do cinema em sala de aula, mas sim apresentar como os saberes docentes determinam as escolhas dos recursos didáticos e metodológicos no ensino de História.

Optamos então, por realizar uma pesquisa com enfoque local na Rede de Ensino de Campo Bom ${ }^{3}$. Essa escolha ocorreu em função de tratar-se de um município que desde o ano de 2009, vem investindo diversos recursos financeiros na área de Tecnologias aplicadas à Educação, atualmente, todas as salas de $1^{\circ}$ a $9^{\circ}$ ano contam com lousas interativas, notebooks e projetores, desta forma os professores que desejam utilizar filmes ou documentários em suas aulas, não encontram empecilhos (como a falta de equipamentos), diferente da realidade encontrada em outras redes municipais, com menos recursos, por exemplo.

Através dessa pesquisa com os professores de História de Campo Bom, buscamos refletir como o cinema vem sendo utilizado pelos professores em suas aulas, e se as metodologias aplicadas alçam os objetivos esperados por eles, tendo como foco o processo de aprendizagem. Uma vez que o cinema pode enriquecer uma aula, desde que utilizado com métodos que estimulem a reflexão e curiosidade dos educandos, orientado-os a interpretar e dialogar com o filme, levando em consideração a fonte histórica que o mesmo representa.

As entrevistas foram formuladas e divididas em três grandes blocos de perguntas, a partir dos saberes docentes segundo Tardif (2002), o primeiro bloco, corresponde aos saberes da formação docente e como estes influenciam a prática em sala de aula, o segundo bloco compete aos saberes curriculares, a própria prática pedagógica do professor e os recursos que utiliza e o último bloco corresponde aos saberes experienciais, advindos das vivências do professor. As entrevistas foram analisadas a partir de alguns historiadores que trabalham com a área da educação e uso do cinema em sala de aula, como Circe Bittencourt (2006), Marcos Napolitano (2011) e Gerson Severo (2004), entre outros.

O uso do cinema como recurso didático nas aulas de História não é algo novo já que o vemos sendo usado em diversas escolas, principalmente pelos professores de História. Esses professores na busca de aproximar os alunos do conteúdo a ser estudado, muitas vezes utilizam os filmes, como um retrato de época ou até mesmo como uma verdade histórica (NAPOLITANO, 2011).

Com isso se objetiva contribuir para a compreensão de como os saberes docentes constroem o perfil do professor e interferem diretamente em sua prática pedagógica e na escolha dos recursos que este utiliza em suas aulas.

\section{OS SABERES DOCENTES E O CINEMA: UMA ANÁLISE}

Para a realização desta pesquisa, foram visitadas as três escolas da Rede Municipal de Campo Bom, e os professores de História foram entrevistados individualmente. O grupo era formado por três homens e duas mulheres, que possuem idade entre 28 e 41 anos de idade, todos concursados no município de Campo Bom.

Foram utilizadas entrevistas estruturadas, utilizando-se da conceituação de análise de dados e de uma pesquisa qualitativa no campo social, que foi construída a partir dos Saberes Docentes, segundo Tardif (2002), em seu livro "Saberes Docentes e a Formação Profissional"”.

\footnotetext{
${ }^{3}$ Município situado na região metropolitana do Estado do Rio Grande do Sul.

${ }^{4}$ Obra esta, a qual leva em consideração um conjunto de fatores que podem e influenciam as práticas docentes, como a formação desses profissionais, suas vivências pessoais, o currículo da rede que atuam seu cotidiano escolar e o entendimento que eles possuem de cinema como fonte histórica.
} 
As entrevistas foram divididas em três grandes blocos de saberes: Saberes da formação docente e disciplinares, curriculares e experienciais. O primeiro bloco de entrevistas constituiu-se da junção dos saberes da formação docente e saberes disciplinares em função de que conforme Tardif (2002), ambos saberes são oriundos e produzidos no mundo acadêmico, logo nessa pesquisa considerou-se pertinente organizá-los em um único bloco e de formação profissional e continuada.

Esta escolha de áreas dos saberes docentes deu-se também em função da importância de se considerar o professor tanto pela sua formação, quanto num processo de auto-formação, que se reelabora a partir dos seus saberes iniciais em confronto com sua prática vivenciada. Assim seus saberes vão-se constituindo a partir de uma reflexão na e sobre a prática. Essa tendência reflexiva vem-se apresentando como um novo paradigma na formação de professores, sedimentando uma política de desenvolvimento pessoal e profissional dos professores e das instituições escolares. Como define Pimenta (1999) sobre a necessidade de ocorrer a:

Significação social da profissão; da revisão constante dos significados sociais da profissão; da revisão das tradições. Mas também da reafirmação das práticas consagradas culturalmente e que permanecem significativas. Práticas que resistem a inovações porque prenhes de saberes válidos às necessidades da realidade. Do confronto entre as teorias e as práticas, da análise sistemática das práticas à luz das teorias existentes, da construção de novas teorias (1999, p. 19).

Para esta entrevista os professores serão denominados professor: A, B, C, D e E, sendo a seguinte correspondência para cada professor:

A: Professor Mestre em História e Especialista em Mídias na Educação, 29 anos, gosta de produzir filmes com os alunos.

B: Professora mestranda em História e Especialista em Estudos Clássicos, 28 anos, é considerada pelos alunos "a professora que passa filmes".

C: Professor Especialista em História da Arte, 28 anos, fã da banda Iron Maden, gosta de trabalhar com músicas em sua.

D: Professora Especialista em Metodologia de História e Geografia, 41 anos, fã dos longas de Asterix e Obelix.

E: Professor Especialista em Educação a Distância, 36 anos, possui uma vasta videoteca. Utiliza sempre filmes originais, em sala de aula.

\section{SABERES DA FORMAÇÃO DOCENTE E O CINEMA NAS UNIVERSIDADES}

Através das entrevistas constatamos que, todos os cinco professores possuem licenciatura em História e, também, possuem especializações na área da Educação, o que demonstra seu interesse em continuarem sua formação, especializando-se em áreas especificas do conhecimento. Para Fiorentini et al. (1998, p. 314), é a partir da década de 80 que percebe-se a importância de se levar em conta os saberes docentes, incluindo dentre estes a formação do professor:

As pesquisas sobre ensino e formação de professores passaram a priorizar o estudo de aspectos políticos e pedagógicos amplos. Os saberes escolares, os saberes docentes tácitos e implícitos e as crenças epistemológicas, como destaca Linhares (1996), seriam muito pouco valorizados e raramente problematizados ou investigados tanto pela pesquisa acadêmica educacional como pelos programas de formação de professores. Embora, neste período, as práticas pedagógicas de sala de aula e os saberes docentes tenham começado a ser investigados, as pesquisas não tinham o intuito de explicitá-los e/ou valorizá-los como formas válidas ou legítimas de saber. 
Neste primeiro bloco de saberes, nos propomos a analisar como a formação dos professores influenciou e influência a sua prática em sala de aula, tanto no que diz respeito às abordagens de ensino, quanto na seleção de conteúdos. Maurice Tardif (2002, p. 257) reconhece a importância do conhecimento provindo da Universidade, porém ele problematiza este conceito, dizendo que nem tudo que se aprende na profissionalização é colocado tal qual, na prática em sala de aula:

A prática profissional nunca é um espaço de aplicação dos conhecimentos universitários. Ela é, na melhor das hipóteses, um processo de filtração que dilui e os transforma, em função das exigências do trabalho; ela é, na pior das hipóteses, um muro, contra o qual se vêm jogar e morrer conhecimentos universitários considerados inúteis, sem relação com o trabalho docente diário.

Ou seja, é um espaço relevante para a prática docente, porém, não consiste na única fonte de conhecimento, na qual os docentes recorrem para seu aparato de conhecimento que será utilizado em sala aula, embora, a Universidade, na maioria das vezes apresente as primeiras noções deste conhecimento que será aplicado na docência.

Neste sentido inicialmente, os professores foram questionados sobre conhecimentos provenientes de seus cursos universitários, que envolvessem a temática do cinema e seu uso em sala de aula. Todos os professores entrevistados relataram que não tiveram em sua graduação uma disciplina específica falando sobre cinema e seu uso em sala de aula. $\mathrm{O}$ professor $\mathrm{C}$ relatou que em seu curso havia uma disciplina eletiva chamada Cinema, Literatura e História, porém ele não cursou a mesma.

Já os professores A, B e D, comentaram que em quase todas as disciplinas do curso de História os professores indicavam filmes sobre determinada temática, "Nas disciplinas de Medieval, e Estudos Clássicos, os professores traziam filmes que falavam sobre o período" (PROFESSOR A). A professora B relatou também que dentro dos componentes específicos do currículo, já era debatido como utilizar determinados filmes dentro do contexto de sala de aula: "Dentro do curso de História, nós utilizávamos o cinema como ferramenta de ensino e aprendizagem". O professor E, relatou que seu contato com filmes, veio do curso de Comunicação, que fazia anterior a licenciatura, e que nessa formação ele aprendeu sobre a influência e as representações dos "vídeos", como ele nomeia.

Embora nenhum dos docentes tenha cursado disciplinas específicas sobre cinema, todos relataram que tiveram disciplinas de Estágio, que faziam a iniciação à docência e nelas eram debatidos e apresentados alguns recursos que poderiam ser utilizados para a obtenção de uma aprendizagem significativa. Esse método de ensino das Universidades é o que Tardif (2002, p.270), apresenta em suas obras onde "os alunos passam um certo número de anos a assistir as aulas em disciplinas constituídas de conhecimentos proporcionais", e somente no final do curso os conhecimentos fragmentados pelas disciplinas, é aplicado, "eles começam a trabalhar sozinhos, aprendendo seu oficio na prática e constatando, na maioria das vezes, que estes conhecimentos não se aplicam no cotidiano" (IDEM).

Percebemos então, que mesmo o currículo cursado pelos docentes não ofertando uma disciplina especifica sobre cinema, este saber também foi adquirido na Universidade, não de uma forma especifica e aprofundada, mas dentro das disciplinas do curso, e também, como veremos posteriormente, pelo próprio interesse de pesquisa sobre a temática, por parte dos professores entrevistados. Para Tardif (2002), estes saberes disciplinares específicos deveriam estar interligados com a prática pedagógica, pois do contrário: 
A lógica disciplinar é regida por questões de conhecimento e não por questões de ação. Numa disciplina, aprender é conhecer. Mas, numa prática, aprender é fazer e conhecer fazendo. No modelo aplicacionista, o conhecer e o fazer são dissociados e tratados separadamente em unidades de formação distintas e separadas (2002, p. 217 272).

Como sugere Marcos Napolitano (2011), o professor de História é o que mais se utiliza, do cinema como recurso didático para suas aulas, caberia à Universidade, portanto repensar sua estrutura curricular redirecionando as relações entre teoria e prática, centralizando-se em assuntos e conteúdos pertinentes a futura prática docente, uma vez que estamos falando sobre cursos de licenciatura ${ }^{5}$.

Outro aspecto importante a ser ressaltado dos saberes disciplinares, trata-se da formação continuada, que consiste em propostas voltadas para a qualificação do profissional, tendo em vista a possibilidade de melhoria de sua prática pelo domínio de conhecimentos e de métodos de seu campo de trabalho.

Todos os professores entrevistados relataram que participam constantemente de formações continuadas (cursos, palestras, seminários, etc.), ofertadas pelo município de Campo Bom. Os professores relatam que formações divididas por área de conhecimento, quase não ocorrem, mas sim formações voltadas às temáticas para educação em geral. Os professores B, D e E, relataram que a última formação que participaram tinha como temática central o Bullying ${ }^{6}$. O professor E, ressaltou a relevância desta temática abordada, "Enriqueceu meu conhecimento, pois é outra área que na faculdade não é desenvolvida". Através desta fala podemos perceber outras lacunas que foram deixadas durante a formação, e que muitas vezes o professor não sabe como lidar quando chega à sala de aula.

Já o professor $\mathrm{A}$, relatou as várias capacitações ofertadas pela rede, na área das tecnologias aplicadas a educação (TIC) relatando que a última que participou, foi justamente sobre este tema. O professor C, participa especificamente do Projeto Ler, que capacita os profissionais a trabalharem diferentes formas de ler o mundo, em sala de aula. Tanto o professor $\mathrm{B}$, quanto o $\mathrm{C}$, relataram que além das capacitações ofertadas pela prefeitura, sempre procuram participar de cursos de extensão em universidades da região e também atualizar-se através da leitura de artigos, sobre diferentes temáticas.

Quanto a formações relacionadas a cinema, os cinco professores relataram que nunca foi ofertado nenhuma capacitação com esta temática pelo município, indo em desencontro com a informação que nos foi passada pela SMEC, de que já haviam sido ofertadas capacitações que envolvessem a temática cinema.

\section{OS SABERES EXPERIENCIAIS E OS RECURSOS FÍLMICOS}

Segundo Tardif (2002, p. 38), os saberes experienciais são os que resultam do próprio exercício da atividade profissional dos professores. Esses saberes são produzidos pelos docentes por meio da vivência de situações específicas relacionadas ao espaço da escola e às relações estabelecidas com alunos e colegas de profissão. Nesse sentido, "incorporam-se à experiência individual e coletiva sob a forma de habitus e de habilidades, de saber-fazer e de saber ser". Uma vez que: "De acordo com nossas análises, é impossível compreender a questão da identidade dos professores sem inseri-la imediatamente

\footnotetext{
${ }^{5}$ Atualmente a estrutura curricular dos cursos de licenciatura possuem mais disciplinas que proporcionem este contato com a prática, através de horas complementares. Também existem programas de iniciação a docência, como o Programa Institucional de Bolsa de Iniciação à Docência - PIBID, financiado pela Coordenação de Aperfeiçoamento de Pessoal de Nível Superior (Capes), é um programa que oferece bolsa para estudantes de cursos de licenciatura plena, para que eles exerçam atividades pedagógicas em escolas públicas de ensino básico.

${ }^{6}$ Termo utilizado para descrever atos de violência física ou psicológica, intencionais e repetidos, praticados por um indivíduo ou grupo de indivíduos causando dor e angústia, sendo executadas dentro de uma relação desigual de poder.
} 
na história de seus próprios atores, de suas ações, projetos e desenvolvimento profissional" (TARDIFF, 2002, p. 107).

As perguntas deste bloco foram elaboradas com o intuito de compreender se os professores entrevistados possuíam contato com filmes em seu cotidiano, quais os gêneros preferidos, se consumiam filmes de canais aberto ou a cabo, se mantinham como hábito idas ao cinema, enfim, se as obras cinematográficas se encontram presentes em seus programas pessoais, culturais e sociais, com o intuito de analisar o quanto os saberes experienciais influenciam em sua prática de sala de aula.

O primeiro questionamento levantado dizia respeito ao hábito de frequentar o cinema, se os professores o faziam e com que frequência. Dos cinco professores entrevistados, quatro relataram que frequentam o cinema habitualmente, entre uma vez por mês ou a cada três meses. O professor $\mathrm{C}$ relatou que não frequenta mais assiduamente o cinema em função do alto preço dos ingressos, os demais professores também comentaram sobre o preço dos ingressos, o que torna o cinema um entretenimento caro, limitando seu acesso ao público em geral.

Como o hábito de ir ao cinema, está interligado com o poder aquisitivo do professor, limitando muitas vezes seu acesso, o próximo questionamento, tinha haver com o hábito de assistir filmes em casa e/ou baixá-los na internet. Todos os professores relataram que tem o hábito de assistir filmes em casa semanalmente. O professor A relatou que baixa filmes da internet, principalmente os ditos "filmes históricos", de ficção científica, zumbis e filmes de guerra, está sempre buscando saber dos últimos lançamentos. A professora B relatou que não tem o hábito de baixar filmes, pois já teve seu computador infectado por vírus, mas os assiste pelo Netflix ${ }^{7}$, relatou que atualmente precisa selecionar o que assiste em casa, em função de ter um filho pequeno, desta forma precisa observar a indicação do filme, e desta forma, limitou sua lista de filmes e do que assiste em casa. O professor $\mathrm{C}$ possui uma biblioteca com mais de 200 filmes, em seu computador, que baixou da internet, prefere os filmes legendados, em função do áudio original. O professor C também assiste filmes pelo Netflix e alguns seriados. Já a professora $\mathrm{D}$, também diminuiu as idas ao cinema, depois que teve filhos, em função de se tratar de um entretenimento caro. Diz-se eclética, no quesito de gênero e procura assistir filmes indicados pelos alunos, para buscar compreender o universo dos adolescentes, o último filme que assistiu, foi Ele está de volta, no Netflix, por indicação dos alunos. O professor E diz que todo o mês vai ao cinema, mas prefere ir às salas de Porto Alegre, pois há maiores promoções no preço do ingresso e descontos para professores. Ele costuma assistir filmes em casa, mas não baixa da internet, segundo ele:

Todos os filmes que eu tenho, eu fiz questão de comprá-los. Eu prefiro ter a capinha para eles olharem, gosto muito de valorizar isto, principalmente os direitos autorais, aquela coisa toda. Gosto de ensiná-los a consumir. A olhar a capinha, vale a pena, não pelo lado material, mas pelo lado de incentivar o consumo do filme (PROFESSOR E, 2016).

Os gêneros preferidos pelo professor E, são os ditos filmes históricos, drama e comédia. Ultimamente vem assistindo diversas series, através do Netflix. Diz sempre estar buscando assistir os últimos lançamentos do cinema, principalmente os da Marvel, pois acompanhava as $\mathrm{HQ}^{8}$, quando era adolescente. Considera bem interessante as trocas que ele consegue fazer com os alunos a partir deste tipo de filme, pois considera que, "O professor tem que entender um pouco do que o aluno vivencia".

\footnotetext{
${ }^{7}$ Netflix é uma provedora global de filmes e séries de televisão via streaming, atualmente com mais de 80 milhões de assinantes. Fundada em 1997 nos Estados Unidos, a empresa surgiu como um serviço de entrega de DVDs pelo correio. A expansão do streaming, disponível nos Estados Unidos a partir de 2007, começou pelo Canadá em 2010. Atualmente, mais de 190 países têm acesso à plataforma.

${ }^{8}$ Histórias em quadrinhos.
} 
A partir dos discursos apresentados até aqui, podemos destacar vários pontos, o primeiro deles, é que, todos os professores entrevistados possuem o hábito de assistir filmes, independente dos recursos e meios que utilizam, podemos perceber que há esta busca e este gosto pelo cinema de maneira geral, mesmo que visto como entretenimento, e isto com certeza se reflete em sua prática em sala de aula, uma vez que, "esta identidade não é somente um "dado", mas também um "constructo", que remete "aos atos" de agentes ativos capazes de justificar suas práticas e dar coerência a suas escolhas" (DUBAR apud Tardif, 2002, p. 107). Também podemos destacar que nenhum dos professores, mencionou a TV a cabo, mas todos mencionaram possuir e utilizar bastante o Netflix, isto se dá devido ao baixo custo desta provedora de filmes, proporcionando que mais pessoas, inclusive os alunos, possam ter acesso a uma cinemateca diversificada. Logicamente este serviço, depende de um bom acesso a internet, uma vez que se utiliza da tecnologia streaming ${ }^{9}$, demonstrando o quanto as tecnologias precisam ser presentes atualmente na vida dos professores, e da população em geral, que busca ter acesso a um conteúdo diferenciado, o que no caso dos docentes faz toda a diferença, em sua prática pedagógica, uma vez que "Sua trajetória social e profissional ocasiona-lhes custos existenciais" (TARDIF, 2002, p. 107). Para Tardif, a importância do saber experiencial está em ele ser também:

Um saber existencial, pois está ligado não somente a experiência de trabalho, mas também a história de vida do professor, ao que ele foi e ao que é, o que significa que está incorporado à própria vivência do professor, à sua identidade, ao seu agir, às suas maneiras de ser (2002, p.110).

Para Napolitano (2011, p.80), o professor que tem o hábito de assistir filmes, consegue trazer está prática para a sala de aula, em função de já estar habituado com a linguagem cinematográfica:

Muitos professores cinéfilos, que dedicam boa parte do seu tempo livre para ir ao cinema ou assistir filmes em casa, já possuem uma boa carga de informação sobre a história do cinema, os filmes, atores e diretores. Toda e qualquer informação poderá ser útil nas atividades em sala de aula, pois torna a análise e a mediação do professor mais interessante.

Outro ponto a ser destacado é como a vida pessoal, do professor interfere em suas vivências, podendo refletir em sua prática, como podemos ver com os professores $\mathrm{B}$ e $\mathrm{D}$, que mudaram seus hábitos, relacionados a filmes, e com certeza, outros que não relataram, em função dos filhos pequenos. Também, destacamos a fala do professor E, que relacionando o hábito de assistir filmes, com a ética, comprando apenas filmes originais e incentivando os alunos a apreciarem e valorizarem o trabalho da empresa que produziu determinado filme. Também podemos perceber pela fala dos docentes, o quanto ocorrem trocas entre professores e alunos, e como eles influenciam tanto na vida cotidiana dos professores, quanto em sua prática em sala de aula. A maioria dos professores entrevistados também ressaltou que pensa ser necessária uma maior aproximação com o universo dos adolescentes, para compreender o que eles vivenciam. Para Tardif (2002, p.108), esta relação de confiança com os alunos, vem com o tempo e com a aquisição de autonomia por parte do professor, uma vez que, "a segurança emocional adquirida em relação aos alunos, o sentimento de estar em seu lugar, a confiança nas suas capacidades de enfrentar problemas e de poder resolvê-los".

\footnotetext{
${ }^{9}$ É uma forma de transmissão de som e imagem (áudio e vídeo) através de uma rede qualquer de computadores sem a necessidade de efetuar downloads do que está se vendo e/ou ouvindo, pois neste método a máquina recebe as informações ao mesmo tempo em que as repassa ao usuário.
} 
Outro questionamento lançado aos professores foi se, os mesmos consideravam o filme como um gerador de práticas sociais. Quatro entrevistados consideraram o cinema comum gerador de práticas e outro professor nunca havia pensado no assunto. O professor A destacou que:

O filme sempre traz uma visão, que muitas vezes a gente não acaba vendo na televisão, que é o canal de comunicação que a maioria das pessoas assiste. Desta forma, assistindo filmes tu acabas tendo acesso a formas de pensamentos variados, e isso pode interferir na questão social de como a pessoa enxerga a sociedade. O filme está aí para quebrar alguns paradigmas, muitas vezes para chamar a atenção, para chocar. Como a polêmica do filme Aquarius, por o elenco se posicionar contra o impeachment da Dilma, gerando uma repercussão, este filme assumiu o papel de resistência, muitos vão assisti-lo por concordar com este posicionamento político, outros passam a questionar (PROFESSOR A, 2016).

Para Nora (1975, p.6), essa análise feita pelo professor A, está completa, pois ele pensou não somente no filme em si, mas em toda a repercussão que ele causou, dos debates que suscitou, e na sociedade que o está vivenciando, pois, "a crítica não se limita somente ao filme, integra-o no mundo que o rodeia e com o qual se comunica necessariamente".

Os professores B e E, relatam que todo o historiador sabe como os filmes influenciaram a sociedade, desde a criação do cinematógrafo pelos irmãos Lumière. O professor $\mathrm{E}$, diz que sempre que fala em cinema, ele recorda-se de como no período da Guerra Fria, os filmes foram utilizados para reforçar ideologias predominantes, segundo ele "Hollywood influência a sociedade ocidental". A professora $\mathrm{D}$, não tem dúvidas de que o filme seja um gerador de práticas, e relatou o seguinte episodio ocorrido em uma de suas aulas:

Ontem uma aluna no $9^{\circ}$ ano me perguntou, quando terminamos um filme: "professora e se hoje existisse a ditadura, hoje a tecnologia é muito mais ampla, e muito mais fácil de se fazer uma rede de investigação". E ela me perguntou aquilo ali, e eles começaram a se colocar no papel de agente social, e aí tu começas a se sentir atuante (PROFESSORA D, 2016).

A partir da análise das entrevistas, deste bloco de saberes experienciais, podemos perceber como as vivências dos professores estão atreladas a sua prática em sala de aula e também o contrario, quanto de sala de aula ele leva em seu cotidiano, a preocupação em compreender o mundo e as vivências do aluno, o assistir filmes, já pensando em como poderão utilizá-los em sala de aula, entre outros aspectos que foram destacados até aqui. Percebemos que todos os professores mostram interesse por assistir filmes de diversos gêneros, e que não o fazem apenas, como espectadores passivos, mas também com um olhar mais crítico e investigativo, próprio do historiador. Desta forma para Tardif (2002, p.109), quanto mais experiências o professor acumular em sua trajetória, mais recursos e ele irá dispor para trabalhar em sala de aula, uma vez que o conhecimento é interativo, "O saber é interativo, mobilizado e modelado no âmbito de interações entre o professor e outros atores. Ele traz por tanto marcas desta interatividade".

\section{OS SABERES CURRICULARES: PRÁTICA E REFLEXÕES}

O último bloco de análises compete aos saberes curriculares, que são os conhecimentos adquiridos ao $\log$ da carreira docentes. Os saberes docentes e a prática pedagógica estão intrinsecamente relacionados, já que é no exercício da prática, uma atividade especializada, que eles são mobilizados, construídos e reconstruídos pelo professor a partir de uma ação dinâmica, ao ensinar. Para o autor: 
Estes saberes correspondem aos discursos, objetivos, conteúdos e métodos a partir dos quais a instituição escolar categoriza e apresenta os saberes sociais por ela definidos e selecionados como modelos da cultura erudita e de formação para a cultura erudita (TARDIF, 2002, p.38)

Para a realização desta pesquisa foram elaboradas questões em que os professores poderiam relacionar os seus saberes com a sua prática em sala de aula, como desenvolvem os conteúdos das aulas de história e o relacionam, ou não, com o nosso objeto de pesquisa em questão, o cinema.

O primeiro questionamento realizado estava relacionado com as ferramentas que os professores utilizavam em suas aulas, uma vez que "os saberes curriculares apresentam-se concretamente sob a forma de programas escolares (objetivos, conteúdos, métodos), que os professores devem aprender a aplicar", (IDEM).

Todos os professores relataram que procuram diversificar suas aulas, não ficando presos apenas ao livro didático, mas sabendo como aproveitá-lo. As professoras B e D, relataram que, desconstroem com os alunos algumas informações e erros dos livros didáticos, sendo que a professora $\mathrm{B}$, sempre informa as editoras, quando encontra alguma informação errônea.

$\mathrm{O}$ professor $\mathrm{C}$ gosta de trabalhar com as obras de arte presente nos livros didáticos, pois são incomuns ao cotidiano do aluno. Tanto o professor A, como o professor E, comentaram que utilizam com bastante frequência das tecnologias disponibilizadas pelo município de Campo Bom, e que elas são facilitadoras do trabalho docente. O professor $\mathrm{E}$ mencionou, que quando chegou ao município, precisou adequar sua forma de dar aula, pois há apenas dois períodos de História, por semana, desta forma ele precisou realizar um trabalho mais dinâmico e produzir seu próprio material didático, adequando assim, suas aulas a nova realidade encontrada.

Os professores também relatam no geral, que trabalham com charges, música, HQ e cinema. A professora $\mathrm{B}$, em função de sua área de estudo, prefere trabalhar com o que ela denomina fontes imagéticas, e destaca a importância de o professor conseguir se adaptar às turmas e ao ambiente de trabalho, afirmando que: "Às vezes o professor quer que os alunos se adaptem ao jeito dele dar aula, mas o professor também tem que se adaptar um pouco ao público em que está".

O professor A destacou que a didática das aulas, muda de acordo com o perfil da turma, mas que em todas, ele disponibiliza cópias, com o resumo da matéria, para não desperdiçar tempo copiando. A professora B, relatou que, no inicio de cada ano letivo faz, "um perfil de cada turma, nele eu coloco as preferências de filmes, programas de TV, livros, e a partir daí começo a planejar". Esse ponto é relevante, pois, vem de encontro com a proposta de Napolitano (2011, p. 80), "a sondagem e avaliação da cultura audiovisual da classe não exigem pesquisa sociológica refinadíssima. Basta que o professor, de maneira informal ou sistematizada, leve em conta algumas informações básicas".

A partir desses relatos percebemos também, uma preocupação em diversificar a maneira de se trabalhar com diferentes abordagens de ensino nas aulas de História. Ressaltamos também o aproveitamento, das tecnologias disponibilizadas pelo município, como a lousa interativa, mostrando interesse e capacitação, por parte dos professores. Destaco também, uma das falas feitas pela professora B, que muito se relaciona com o oficio docente: "Ser professor, é meio que isto, viver cotidianamente com o sucesso e o fracasso". Dessa forma percebemos que ao analisarmos os instrumentos que os professores utilizam para suas aulas, podemos visualizar melhor seu perfil docente e como ocorrem suas práticas. Tardif (2002, p, 225), conceitua prática profissional, como sendo "o estudo do conjunto de saberes utilizados realmente pelos profissionais em seu espaço de trabalho cotidiano para desempenhar todas as suas tarefas". 
Como todos os professores relataram que utilizavam cinema em sala de aula, o próximo questionamento foi se consideravam o cinema como fonte histórica e se utilizavam fontes históricas em suas aulas. Os professores A, B e C, consideram o cinema como fonte histórica. Segundo o professor A:

O cinema, ele diz muito sobre aquelas pessoas que estavam fazendo o filme, a abordagem que tiveram o porquê daquela forma e não de outra. Então o cinema é historicamente datado, foi feito daquela forma de acordo com as pessoas daquela época.

Essa fala do professor A, condiz com o já citado anteriormente, baseado em Ferro, Baldissera e outros. O cinema é uma fonte para compreender a sociedade que o produziu, para Ferro (1992), o cinema é a testemunha ocular do seu tempo. O professor $\mathrm{C}$ relata o seu interesse em posteriormente estudar a linguagem específica do cinema, para poder aproveitar melhor este recurso em sala de aula. Ele diz assistir alguns canais do You Tube, que abordem esta temática. Para Napolitano (2012, p.57), "o professor não precisa ser um crítico profissional de cinema para trabalhar com filmes em sala de aula. Mas o conhecimento de alguns elementos de linguagem cinematográfica vai acrescentar qualidade ao trabalho".

Os professores D e E, não consideram o cinema como uma fonte histórica. Alegando que a história real do filme, sempre é modificada para poder alcançar altos índices de bilheteria, o que torna a história representada, não fidedigna. A problemática nestes discursos está em consideraram somente a história que está sendo narrada pelo filme, sem levar em conta outros aspectos. Isto se dá, segundo Bittencourt, por que os professores não percebem que "A imagem não ilustra nem reproduz a realidade, como acreditava Serrano em seu livro didático, mas reconstrói a realidade com base em uma linguagem própria, produzida em determinado contexto histórico" (2011, p.373).

Também podemos trazer novamente a ideia de Severo (2004, p.35), de que "todo filme é histórico", depende da forma e da metodologia investigativa, conduzida pelo professor. Outra questão que podemos levantar é qual o conceito de fonte histórica, que estes professores possuem? Porque se não tiverem claro para si, poderão fazer acepções e menosprezar fontes não consideradas tão fidedignas, como fontes oficiais, como acontecia antes do advento da escola dos Annales ${ }^{10}$. A própria professora B, que trabalha utilizando fontes imagéticas, relatou que dentro da sua própria Universidade, sofre preconceito de alguns historiadores, por utilizar a imagem como fonte para pesquisa.

Outra questão levantada, dentro desta pergunta, foi, se os professores utilizavam fontes históricas em suas aulas. Os professores A, B, D e E, relataram que trabalham com fontes em sala de aula. Os três disseram que utilizam trechos de documentos, fotografias, jornais e revistas, projetados na lousa interativa, fazendo analise dos mesmos com os alunos. O professor A, relatou que também utiliza acervos on-line, para os alunos visitarem, quando vão à sala de informática. A professora $\mathrm{B}$, relatou que realizou um trabalho de analise de pôsteres da Revolução Russa, e que foi bastante significativo para a aprendizagem dos alunos. A professora D ressaltou, da importância de se trabalhar com fontes históricas, alegando que "é importante os alunos saberem como se faz História". Bittencourt (2011, p.333), nos fala da pertinência do uso das fontes históricas em sala de aula:

O uso de documentos nas aulas de História justifica-se pelas contribuições que pode oferecer ao desenvolvimento do pensamento histórico. Uma delas é facilitar a compreensão do processo de produção do conhecimento histórico pelo entendimento de que os vestígios do passado se encontram em diferentes lugares.

\footnotetext{
${ }^{10}$ A Escola dos Annales foi um movimento de renovação da historiografia iniciado na França do final da década de 1920, com a fundação, por Marc Bloch e Lucien Febvre, da revista Anais de História Econômica e Social.
} 
Dessa forma vemos que, no caso, desses professores entrevistados, os mesmos têm a preocupação de utilizar fontes em sala de aula, enriquecendo a vivência dos alunos. Já, o professor C relatou não utilizar fontes, em suas aulas, pois é difícil organizar saídas de campo para museus e acervos de pesquisa. Nessa fala percebemos uma limitação na conceituação do que seria considerada fonte histórica, uma vez que "será equivocado caso se pretender que o aluno se torne um pequeno historiador, uma vez que, para o historiador o documento tem outra finalidade, que não pode ser confundida com a situação do Ensino de História" (BITTENCOURT, 2011, p. 328). Podemos notar também que, embora os professores citassem anteriormente que consideram o cinema como uma fonte histórica, ele não foi citado, nessa questão, como uma das fontes que os mesmos utilizavam em suas aulas. Todos referiram-se a fontes mais "tradicionais" da História.

Também foi questionado aos professores, se eles recorriam sempre ao filme completo, ou preferiam utilizar trechos, como proposto por Severo (2004), Napolitano (2011) Bittencourt (2011), entre outros autores que abordam esta temática, até mesmo para resolver a problemática do curto período que os professores de História dispõem semanalmente.

O professor A, relatou que normalmente trabalha só com trechos de filmes, em função do tempo. Para Vessentini (2006, p. 165), "entender filmes como parte de um curso supõe, no mínimo, o mesmo trabalho oferecido a outros documentos ou textos da bibliografia", desta forma não há necessidade de passa-los na integra, mas sim subdividi-los escolhendo os trechos desejados.

A professora B relata que normalmente passa o filme na integra, mas as vezes seleciona trechos de filmes, que abordem a mesma temática e os compara com os alunos, esta proposta assemelha-se a feita por Servero, quando este diz que "cinema é metáfora" (2004, p.128), e dessa forma diferentes recortes podem ser comparados, analisados e discutidos, numa abordagem conceitual.

$\mathrm{O}$ professor $\mathrm{C}$, prefere utilizar os filmes na integra, relatando que:

Na faculdade me disseram: não usa o filme inteiro, professor que usa filme inteiro é pra matar aula. Eu não acho. Algumas vezes eu uso o filme para passar o conteúdo inteiro, como no caso da reforma protestante com o filme Lutero (2004).

Porém nesse caso, precisa-se ter o cuidado para que o filme simplesmente não sirva para "substituir o lugar da fala do professor" (SEVERO, 2004, p. 99), e muito menos para passar um conteúdo completo. $\mathrm{O}$ professor $\mathrm{C}$, também relatou que costuma utilizar trechos de seriados, para ilustrar alguns contextos, como o seriado Vikings ${ }^{11}$. O trabalho com séries, que cada vez estão mais presentes no cotidiano do brasileiro, atualmente, é de grande importância, pois ela s também podem servir de instrumento investigativo sobre a sociedade que o produziu:

Filmes, minisséries, documentários e docudramas históricos de grande bilheteria, são gêneros cada vez mais importantes em nossa relação com o passado e para nosso entendimento da História. Deixá-los de fora da equação quando pensamos o sentido do passado significa nos condenar a ignorar a maneira como um segmento enorme da população passou a entender os acontecimentos a as pessoas que constituem a História (ROSENSTONE apud BALDISSERA, 2014, p.33).

A professora $\mathrm{D}$ prefere utilizar os filmes completos, pois os alunos gostam muito do desfecho das narrativas, porém, quando se trata de filmes que ela considera, "mais parados", como 1492 A conquista do Paraíso (1992), ela prefere utilizar apenas trechos.

${ }^{11}$ Vikings é uma série de televisão irlando-canadense, um drama histórico escrito e criado por Michael Hirst para o canal de televisão History. Estreou no ano de 2013 e ainda vai ao ar, estando na $4^{\text {a }}$ temporada. 
O professor E, para otimizar o tempo de sua aula, normalmente utiliza trechos de filmes, porque considera que "o aluno não pode pensar que a aula de História é só filme, é preciso variar a dinâmica". O professor também relata que em alguns momentos da aula, existem conteúdos e assuntos, que são tão distantes da realidade do aluno, que somente ele visualizando um recorte fílmico, que represente determinada situação, ele consegue conceituar e compreender a aula. Nas palavras do entrevistado:

O aluno não tem noção do que é uma guerra, nem eu tenho, para ser sincero, porque nós nunca estivemos numa guerra para saber, mas eu já passei trechos de como funciona uma trincheira. Tem vários filmes apontando isso, como o início do filme d’O Resgate do Soldado Ryan (1998).

Assim como a professora $\mathrm{D}$, o professor $\mathrm{C}$, também compilou trechos do filme 1492 A conquista do Paraíso, e relata que vários colegas seus, não dominam ferramentas tecnológicas para realizarem estes recortes nos filmes, mas para ele: "É importante qualquer professor hoje, ter o domínio de alguns programas para pegar um filme e tirar as partes desnecessárias”. A fala do professor E faz um paralelo com Vessentini (2006, p.165), quando este aborda que subdividir um filme "é difícil devido o tempo exigido, mas por ela o professor amplia tanto o seu domínio sobre o filme, quanto define melhor uma bibliografia de leitura prévia para o trabalho com o filme".

Percebemos até aqui, que embora os professores utilizem filmes completos, em dados momentos da disciplina, recorrem mais a trechos das obras, para aproveitarem melhor os períodos da disciplina. Demonstra também um planejamento prévio por parte dos docentes. Severo (2004, p.68), reflete sobre o uso dos trechos, dizendo que, "uma vez bem escolhido, e sim, mesmo que somente um trecho, o filme poderá garantir que o conteúdo aprendido não seja arbitrário e aleatório".

Quando questionados, sobre, quais conteúdos os professores mais recorriam ao uso do cinema, todos os entrevistados responderam que utilizavam filmes no fechamento de quase todos os conteúdos.

A professora B relatou que sempre recorre ao uso de filmes quando trabalha a Revolução Francesa, pois os alunos têm dificuldade em compreender este conteúdo. Já o professor C, sempre utiliza filmes no conteúdo de mitologia grega, para que os alunos possam compreender a relação entre deuses e humanos. Percebemos por estes relatos, que o uso do cinema, assim como sugere Severo (2004), é recorrente nas aulas de História, e também vemos que os professores têm claro, quais conteúdos os alunos têm mais dificuldades de aprendizagem, e utilizam o cinema como uma ferramenta para ilustrar, como sugere que, "O vídeo muitas vezes pode ajudar a mostrar o que se fala em aula, a compor cenários desconhecidos dos alunos" (MORAN apud NAPOLITANO, 2011, p.35).

Quando questionados se preferiam utilizar filmes mais antigos ou novos, os professores responderam que essa escolha depende muito do filme e do perfil da turma que estão trabalhando. A professora B, destacou que existem filmes atemporais, que os alunos gostam muito, como os de Charles Chaplin, Tempos Modernos e $O$ grande Ditador. Relatou também, que gosta de assistir com os alunos o documentário $O$ triunfo da vontade que foi produzido em 1935, a pedido do Terceiro Reich. Segundo a professora os alunos sempre perguntam: "Sora, aquele ali é o Hitler mesmo? Não é um ator? Olha o jeito com que ele discursava", diz também que não passa filmes $C u l t^{12}$, pois não prende a atenção dos alunos em função de ser uma linguagem que os alunos não são acostumados a assistir.

$\mathrm{O}$ professor $\mathrm{C}$ relatou que na temática mitologia grega, prefere utilizar filmes mais antigos que abordem esta temática, pois filmes mais contemporâneos como Percy Jackson e o Ladrão de Raios

12 É o termo designado para filmes que não tem preocupação em agradar o público, possui um roteiro original, às vezes, transgressor contendo o bizarro, sexo e violência, apelam para uma estética alternativa, costumam ter personagens estranhos, também não segue a fórmula comercial hollywoodiana. 
(2010), ele considera que traz muitas "informações erradas" e anacronismos. A professora D gosta de trazer para as salas de aula os últimos lançamentos de super-heróis, pois abordam bem o período entre guerras, a indústria bélica, o fortalecimento das nações, desta forma trabalhou em sala de aula com um filme do universo Marvel, O Homem Formiga (2015), onde trabalhou a questão da alta tecnologia aplicada à guerra, mísseis, drones entre outros.

Dessa forma, percebemos que é preocupação dos professores utilizar obras cinematográficas, que facilitem a compreensão dos alunos para com o conteúdo, pois como nos traz Napolitano (2011, p.80) "não tente impor seu gosto cinematográfico aos alunos, faça-os exercitar o olhar cinematográfico com base em filmes mais assimiláveis". Também destacamos que no caso do professor C, é interessante se trabalhar com as informações erradas dos filmes, fazendo com os alunos um exercício reflexivo, entre o conteúdo e o filme. Baldissera (2014, p.149) aborda a questão dos anacronismos presentes no filme a Guerra de Troia (1961):

Muitos historiadores viram nestas questões, uma série de anacronismos; mas vale recordar que a própria poesia de Homero é recheada de anacronismos conscientes, uma vez que mesclava história e mito e precisava ser compreendida por gerações muito posteriores. Que talvez só tivessem conhecimento de uma possível guerra contra Troia, através de Homero.

Cabe ao professor, conduzir a aula e o conteúdo, proporcionando a desconstrução destes erros e anacronismos, contribuindo para a formação de um aluno com visão crítica do que assiste, pois para Bittencourt (2006, p. 19), "a constituição de um pensamento crítico é uma meta necessária para as sociedades em transformações".

O último questionamento feito aos professores foi referente à recepção dos alunos quanto ao uso dos filmes em sala de aula, uma vez que é essencial para uma aprendizagem significativa que o aluno esteja envolvido e atribua um significado a determinado conteúdo, pois do contrário:

O professor literalmente lança sobre o aluno o conteúdo da disciplina, em uma tentativa, quase sempre desastrada - e por isso agravadora do quadro de desmotivação - de vencer a dificuldade de comunicação e seus efeitos impeditivos para a consecução satisfatória de uma aula (SEVERO, 2004, p.51).

Quatros, dos professores entrevistados, comentaram que os alunos gostam muito, desses momentos com filmes. Também relataram que nunca passam um filme de surpresa, mas sim, que realizam um trabalho prévio e marcam com os alunos quando irá assistir a um filme, demonstrando que houve planejamento por parte dos professores e que os não estão utilizando como "vídeo enrolação ou tapa-buracos" (MORAN apud NAPOLITANO, p.34). O professor E, relatou que além de estudo, os alunos veem o cinema em sala de aula, como um momento de prazer, pois há turmas que até trazem pipoca, segundo ele isto se dá: "porque eu não passo filmes toda a hora, porque se eu passasse toda hora, ia banalizar". Este conceito de banalização que se dá em função do excesso de utilização de uma determinada ferramenta é o que Moran (IDEM), chama de "vídeo deslumbramento, o professor que acaba de descobrir o uso do vídeo, costuma empolgar-se e passa vídeos em todas as aulas".

A professora B, relata que é conhecida pelos alunos, como a "professora que passa filmes", e sempre que chega a sala os alunos questionam: "Sora, vai ter filme hoje?", mas ela também fala sobre a importância de diversificar as ferramentas de ensino.

Já para o professor $\mathrm{C}$, a receptividade dos alunos quanto aos filmes, pode não ser tão positiva, quanto se espera. Segundo ele: "É complicado, quando tu fala que vai passar filme, eles já acham que 
tu vai passar Invocação do Mal, Anabelle, Velozes e Furiosos, ou qualquer outra coisa. Os alunos já pensam: Oba, vamos ver filme! Não vai ter aula!".

Esta problemática vivenciada pelo professor C, pode estar ocorrendo, em função de em outros momentos, ou em outras aulas, eles terem sidos submetidos ao "vídeo tapa-buraco, colocar vídeo quando há um problema, como a ausência de um professor [...] desvalorizando o uso do vídeo e associando, na cabeça do aluno, a não ter aula" (MORAN apud NAPOLITANO, p.34). Para Bittencourt (2011, p. 376), o professor deve questionar os alunos, que tipo de entretenimento estão consumindo pois, "é preciso preparar os alunos para uma leitura crítica de filmes, começando por uma reflexão sobre os próprios a que eles assistem. Como escolhem um filme para assistir, ou quais os atraem?". Assim, cabe ao professor ser o mediador entre o conhecimento que os alunos trazem se suas vivências e experiências, promovendo situações, com o uso de determinados filmes, que os façam refletir sobre o que consomem em seu cotidiano, pois como destacou a professor B: "O problema dos alunos é que eles não sabem contextualizar, e é aí, que entra o professor, contextualizando e problematizando".

Para Tardif (2002), o professor é, antes de tudo, alguém que sabe alguma coisa e ensina a alguém e, para isso, atua a partir de diversos saberes que alicerçam o seu trabalho, como: o saber da formação profissional, disciplinares, curriculares e o saber da experiência, enfatizando que "no exercício de suas funções e na prática de sua profissão, desenvolvem saberes específicos, baseados em seu trabalho cotidiano e no conhecimento de seu meio" (2002, p. 38). Através do que foi dito e analisado até aqui pelos professores, é fundamental destacar a maneira singular de como cada docente trabalha e conduz a sua disciplina, e muito embora todos lecionem com a disciplina de História, conseguimos perceber o perfil de cada docente, e como os saberes influenciam no seu "saber-fazer", como nos é trazido por Tardif. Transformar a sala de aula em um ambiente significativo e motivador, e perceber quando o professor faz conexões com o conteúdo, faz toda a diferença na prática educativa, muito diferente de quando o filme só é um tapa-buracos ou substitui o desenvolvimento do conteúdo.

Outro ponto a ser destacado, é a questão da busca por aprimorar, sua maneira de ensinar. Tanto no que diz respeito em trazer novas metodologias e novas fontes para sala de aula, quanto a pesquisas sobre novos filmes, como aprimorar a sua prática em relação à utilização dos mesmos, e até, como citou o professor E, procurar conhecer ferramentas tecnológicas para manipulação/edição, dos filmes. Freire (1996, p.29) vem afirmar que:

Não há ensino sem pesquisa e pesquisa sem ensino. Esses afazeres se encontram um no corpo do outro. Enquanto ensino, continuo buscando, reprocurando. Ensino porque busco, porque indaguei, porque indago e me indago. Pesquiso para constatar, constatando intervenho, intervindo educo e me educo. Pesquiso para conhecer, o que ainda não conheço e comunicar ou anunciar a novidade.

\section{CONSIDERAÇÕES FINAIS}

Em nenhum momento esta pesquisa teve o objetivo de realizar avaliações acerca da atuação dos professores da Rede de Ensino Fundamental, mas sim analisar propostas relativas ao uso do cinema em sala de aula e como este recurso pode ser uma ferramenta para uma aprendizagem significativa. Também ressaltamos que este projeto não é detentor da verdade, é apenas o início de um estudo que traz algumas sugestões do uso do cinema, bem como sua relevância como recurso didático para as aulas.

Ao longo da pesquisa e pela análise das entrevistas, foi possível perceber que todas as escolas são muito bem equipadas, disponibilizando lousas interativas e sistema de áudio em todas as salas, facilitando assim o trabalho do professor, que não necessita de agendamento prévio por parte do professor. Percebemos que o município, considera importante o trabalho com filmes, porém ainda não 
proporcionou capacitações nessa área específica, pois opta por seminários gerais, para os professores, com temas mais abrangentes sobre a educação.

Constatamos também, que os professores entrevistados utilizam com constância esses equipamentos tecnológicos disponibilizados pelo município, sendo as lousas na hora de assistir os filmes, ou câmera, telas verdes e editores de imagens, quando produzem os curtas metragens juntamente com os alunos, conseguindo promover uma aprendizagem significativa a partir da utilização das novas tecnologias e mídias voltadas para a educação.

Observamos que todos os professores, planejam antecipadamente as atividades que propõe as suas turmas, além do mais as atividades propostas possuem objetivos bem delineados, o que é fundamental para uma boa aula. Pois vários citaram a produção de filmes, o recorte de obras, a análise de recortes diferentes, a produção de maquete, entre outros, que só são possíveis de se executar com um planejamento prévio. Percebemos também um interesse dos professores, quanto a temática cinema, e como esses, apesar de formados, continuam buscando informações, tanto em cursos, quanto em sites e artigos, sobre a linguagem do cinema, sobre novos métodos de ensino e até mesmo sobre novos filmes, que acrescentem em sua biblioteca. Demonstrando assim, que um bom professor, é um eterno pesquisador, na busca por aprimorar sua prática pedagógica.

Através das entrevistas percebemos também que, a temática "cinema" esteve presente na vida acadêmica dos professores, porém eles não estudaram como usar o cinema em sala de aula, apenas discutiam como determinado filme, representava tal período histórico. O que é uma abordagem, que pode ser feita, mas o trabalho com filmes pode ser tão mais significativo e rico em aprendizagem, do que apenas ilustrar períodos, como vimos no decorrer desse trabalho. Analisando esse fato e a maneira que estão sendo estruturadas as novas licenciaturas, acreditamos também, que a Universidade possa proporcionar mais momentos para a iniciação a docência, pois como os professores entrevistados relataram, só no final do curso é que se tem a vivência em sala de aula propriamente dita, nas disciplinas de estágio, e quem não participou de programas como o PIBID (Programa de Iniciação a Docência), sente-se muitas vezes inseguro para inovar em suas abordagens de ensino e acaba recorrendo a maneiras mais fáceis, como o livro didático.

Analisamos nessa pesquisa também, o quanto a experiência pessoal influencia a prática docente e percebemos que esta influência, vai desde a escolha das ferramentas, pois o professor que é fã de bandas, sempre recorre a músicas, a professora que trabalha com imagens, o mesmo, entre outros exemplos citados aqui. Percebemos que todos os professores, mesmo quando fazem programas pessoais, como assistirem filmes, ou navegarem na internet, sempre pensam em seus alunos, de como tal filme poderia ser usado com determinada turma, ou tal poderiam usar tal recorte outro filme que foram no cinema assistir, ou que assistiram uma obra por indicação de algum aluno. Percebemos que a família influencia a prática, uma vez que os filhos dos professores, algumas vezes, limitam o que eles assistem em casa e posteriormente levam para a sala de aula, uma vez que determinado filme, não se pode assistir com crianças por perto, ou até mesmo as idas ao cinema que diminuíram, pois a prioridade são programas onde os filhos possam ir junto. Então percebemos que o professor é misto de todas as coisas que lhe cercam e traz consigo influência todos os papeis sociais que desempenha, porém foi constatado que o cinema está presente tanto em seu lado pessoal, como profissional.

Com essa pesquisa, percebemos que a escolha por se utilizar o cinema em sala de aula, está diretamente ligado com os Saberes Docentes trazidos por Maurice Tardif, que serviram de base para estruturar as entrevistas da presente monografia. Uma vez que pudemos perceber que os professores são constituídos por distintos saberes e influências. Nesses casos não existem exceções, o pessoal do professor está vinculado no seu profissional, e vice-versa, ambos trabalham unidos para que se construa 
"o professor". Dessa maneira, percebemos o professor sofre influências tanto de sua formação, quanto de suas vivências e essas auxiliam ou interferem no desenvolvimento de sua prática docente.

\section{REFERÊNCIAS}

BALDISSERA, José Alberto; RUINELLI, Tiago de Oliveira. 'Tempo e Magia' - A história vista pelo Cinema. Porto Alegre: Escritos, 2014.

BITTENCOURT, Circe Maria Fernandes. Ensino de história: fundamentos e métodos. São Paulo: Cortez, 2011.

Capitalismo e cidadania nas atuais propostas curriculares de História. In: BITTENCOURT, Circe. O saber histórico em sala de aula. São Paulo: Contexto, 2006, p. 11-28.

FIORENTINI, D.; SOUZA e MELO, G.F. Saberes docentes: Um desafio para acadêmicos e práticos. In: GERALDI, C (org). Cartografias do 42 Educação \& Sociedade, ano XXII, nº 74, Abril/2001 trabalho docente: Professor(a)-pesquisador(a). Campinas: Mercado das Letras, ALB, 1998.

FLORESCANO. Enrique. A função social do historiador. Tempo Revista do Departamento de História da UFF, Rio de Janeiro, 1997, vol. 4. p. 66-68.

FREIRE, P. Pedagogia da autonomia: Saberes necessários a prática educativa. São Paulo, 1996.

NAPOLITANO, Marcos. A História depois do papel. In: PINSKY, Carla Bassanezi. Fontes Históricas. 3. Ed. São Paulo: Contexto, 2014, p. 235-291.

A Escrita fílmica da história e a monumentalização do passado: uma análise comparada de Amistad e Danton. In: História e Cinema: Dimensões do audiovisual, org: Maria Helena Capelato...[et. al.] 2a Ed. São Paulo: Alameda, 2008, p. 65-84.

. A televisão como documento. In: BITTENCOURT, Circe. O saber histórico em sala de aula. São Paulo: Contexto, 2006, p. 149-162.

. Como usar o cinema em sala de aula. $5^{\text {a }}$ Ed. São Paulo: Contexto, 2011.

PIMENTA, S. G. Formação de professores: Identidade e saberes da docência. In: PIMENTA, S.G. (Org.). Saberes pedagógicos e atividade docente. São Paulo: Cortez, 1999.

SEVERO, Gerson Egas. Com Lumière em sala de aula: uma contribuição. Erechim: Edifapes, 2004.

TARDIF, Maurice. Saberes docentes e formação profissional. Petrópolis: Vozes, 2002. 